\title{
Capítulo 10 \\ Parámetros generales para la edición de videos en YouTube
}

\author{
Juan Pablo Montalvo Valencia \\ Universidad Politécnica Salesiana, Ecuador \\ Orcid: https://orcid.org/oooo-ooo3-1567-0181 \\ Edwin Rene Yunga \\ Universidad Politécnica Salesiana, Ecuador \\ Orcid: https://orcid.org/oooo-ooo3-3050-5432 \\ DOI: https://doi.org/ 10.16921/ciespal.14.12
}

\section{Resumen}

Hoy más que nunca, el mundo depende del Internet, más de la mitad de la población mundial está conectada en la red y los contenidos que los usuarios comparten son parte activa de esta conexión. YouTube es una plataforma que, desde su creación en el 2005, ha permitido que sus usuarios compartan sus propios videos con distintos fines, entre ellos, educativos, de entretenimiento y de negocios. Con el paso de los años y gracias a la evolución tecnológica, los usuarios se han beneficiado de mayores facilidades a la hora de crear videos, editar y publicar en la web. Producir un video con detalles y características propias es más sencillo y está al alcance de todos, es suficiente disponer de tener un teléfono inteligente y una aplicación para crear contenidos. Millones de videos son creados cada segundo y su impacto en la sociedad es incalculable, capaz de salvar vidas, derrocar gobiernos, influenciar positiva o negativamente en las personas.

Palabras clave: Edición de video; YouTube; Adobe Premiere Rush. 
Abstract

Today, more than ever, the world depends on the Internet. More than half of the world's population is connected to the network and the content that users share is an active part of this connection. YouTube is a platform that, since its creation in 2005, has allowed its users to share their own videos for different purposes, including educational, entertainment and business. Over the years and thanks to technological evolution, users have benefited from greater facilities when creating videos, editing and publishing on the web. Producing a video with its own details and features is easier and more affordable for everyone, it is enough to have a smartphone and an application to create content. Millions of videos are created every second and their impact on society is incalculable, capable to influence lives, overthrowing governments, positively or negatively influencing people.

Keywords: Video edition; YouTube; Adobe Premiere Rush.

YouTube se concibió como una plataforma en donde cualquier persona puede subir sus videos para compartir actividades de la vida cotidiana y novedades dentro de sus círculos sociales sin costo alguno. Esta idea fue materializada el 14 de febrero del 2005 por tres ex empleados de Paypal, Steve Chen, Jawed Karim y Chad Hurley, quienes se dieron cuenta de la dificultad para compartir videos a través de la web. YouTube nace bajo el lema Broadcast Yourself (retransmítete a ti mismo), una página web relativamente sencilla de usar, donde no hay necesidad de registrarse para ver un video, aunque para subirlo se debe crear una cuenta de usuario. Con el aparecer de los primeros influencers propios se acuño el término YouTubers para identificar a las personas que se dedicaban a crear contenidos en la plataforma con diversos con fines. El 9 de octubre del 2006 Google adquiere YouTube por un precio de 1.650 millones de dólares y a partir de entonces se han dado numerosos cambios en cuanto a su infraestructura digital, convirtiéndose en más simple y amigable para el usuario final (Bouillot, 2018). En la actualidad, los usuarios de YouTube pueden realizar cosas 
que hace mucho eran impensables, como las transmisiones de video en vivo, la publicación de videos en realidad virtual, el uso de resoluciones cinematográficas y la reedición de video en línea gracias al sistema de computación en la nube que ofrece YouTube de forma gratuita. En este capítulo se presenta el uso de las herramientas al alcance del usuario ofreciendo pautas sobre cómo crear videos desde cero, publicarlo con éxito respetando las normas y comenzar a ser parte de esta revolución del video en Internet.

\section{Preparando y entendiendo a los equipos de trabajo}

Desde el año 2006, comenzó la introducción de la tecnología Full HD en el ámbito audiovisual (Cianci, 2012), desde entonces los dispositivos digitales han evolucionado de tal manera que en la actualidad existen equipos capaces de filmar y reproducir imágenes en resoluciones superiores. Gracias a estos avances es posible, en la actualidad, adquirir hoy un teléfono móvil de media gama con cámaras incorporadas de una calidad y precio muy aceptable. Usualmente los teléfonos son equipados con una aplicación (app) que disminuye la calidad de entrada de la imagen en el dispositivo debido al lavado de imagen que genera la misma app, borrando todo rastro de ruido digital lo cual, en varias ocasiones, hace que los videos o fotos se vean mal. (Ochoa, 2016) Por este motivo se recomienda instalar una aplicación específica para la grabación de imágenes lo que consiente desactivar el reductor de ruido y grabar videos o tomar fotos con la calidad real. Las apps más recomendadas por los profesionales del sector son Filmic Pro y Procam $\mathrm{X}$. Tambien es recomendable adquirir un telefono con Minimo 64, Gb de almacenamiento interno porque el sistema operativo, sus aplicaciones y los contenidos que se generen, pueden consumir mucha memoria (Serrano, 2017).

Para poder editar videos con una buena calidad es necesario disponer de un PC con caracteristicas especificas. Es importante que la 
computadora que se utilice tenga equilibrio entre sus especificaciones tecnicas para que todos los softwares y aplicaciones funcionen al maximo rendimiento y se eviten posibles congelamientos. No es necesario que el PC disponga de un procesador de ultima generación, a menos que no se desee alcanzar los niveles de la edición cinematográfica, para la cual se usan tecnologia de soporte para alta resolución de video y gráficos complejos (Carrasco, 2010). En las tablas 1 y 2 se presentan los requisitos recomendados en base a la resolucion de video (HD y FullHD), tanto para computadoras como para smartphones o tablets.

Tabla 1. Requisitos mínimos para editar videos con resolución HD

\begin{tabular}{|l|l|l|}
\hline Características & Computadoras & Teléfonos \\
\hline Procesador & 13 a $2.5 \mathrm{Ghz}$ & Exynos $7884.2 \mathrm{a} 1,6 \mathrm{GHz}$ \\
\hline Memoria Ram & $4 \mathrm{gb}$ o $6 \mathrm{gb}$ & $3 \mathrm{~Gb}$ \\
\hline Tarjeta de video & integrada lgb & Mali-G71 o similar \\
\hline Disco duro & $200 \mathrm{~Gb}$ & $64 \mathrm{gb}$ internos \\
\hline
\end{tabular}

Fuente: autores

Tabla 2. Requisitos mínimos para editar videos con resolución Full HD

\begin{tabular}{|l|l|l|}
\hline Características & Computadoras & Teléfonos \\
\hline Procesador & 15 a 3Ghz & Exynos 7904 a 1,8 GHz \\
\hline Memoria Ram & $8 \mathrm{gb}$ & $6 \mathrm{~Gb}$ \\
\hline Tarjeta de video & dedicada 4gb a 1,4Ghz & Mali-G71 - MP2 \\
\hline Disco duro & SSD 256Gb & 128gb internos \\
\hline
\end{tabular}

Fuente: autores 


\section{Antes de comenzar a editar: reuniendo recursos de Internet}

Dependiendo del objetivo planteado al momento de crear un video, es posible incluir varios elementos lingüísticos y extralingüísticos como textos, música, efectos de sonido, otros videos y hasta imágenes. Son los ingredientes básicos que dan vida al video, que se seleccionan con atención respetando normas y leyes que protegen tanto la propiedad intelectual de los autores como la sensibilidad de los públicos que los visualizaran. Desde el 2007 YouTube ha creado un filtro para la publicación de videos en su plataforma que funciona gracias a algoritmos capaces de detectar contenido propiedad de terceros y contenidos considerados como censurables. Mediante este mecanismo es posible denunciar posibles infractores, tanto en el caso de las empresas y personas propietarias de estos contenidos, como en el de las personas afectadas por el contenido de un video. Como medida de resguardo se puede solicitar el bloqueo del video (y su contenido), o monetizarlo a través de publicidad añadida (Torres Ripa \& Gómez Hernández, 2011).

Para poder facilitar la recolección de los recursos necesarios, se ha preparado una lista con varios repositorios que suelen alojar contenidos multimedia como videos, fotografías, gráficos o música, mismos que pueden tener una licencia gratuita o de paga. Se recomienda leer las condiciones de la licencia que debe tener cada contenido antes de la descarga. En el caso de encontrar contenido sujeto a una licencia gratuita, lo normal es que su autor consienta el uso a cambio de la correcta atribución de la autoría la cual se coloca en la descripción del video. Usualmente los creadores de video solicitan la atribución explicita de autoría mediante una licencia Creative Commons la cual tiene variantes y condiciones específicas a protección de los autores que consideran acciones como la solicitud de retribución, la restricción de la monetización de un video, la prohibición de derivados de sus obras y aplicación en otras condiciones (Creative Commons, 2020). 
Tabla 3. Lista de páginas web recomendadas para la descarga de recursos.

\begin{tabular}{|l|l|l|}
\hline Sitio Web & Tipo de recursos & Tipo de Licencia \\
\hline YouTube.com/audiolibrary & $\begin{array}{l}\text { Música y efectos de } \\
\text { sonido }\end{array}$ & $\begin{array}{l}\text { Gratuita bajo con- } \\
\text { diciones }\end{array}$ \\
\hline www.pixabay.com & $\begin{array}{l}\text { Imágenes, música, vi- } \\
\text { deos, gráficos }\end{array}$ & Creative Commons \\
\hline www.freepik.es & Gráficos & Creative Commons \\
\hline www.freesound.org & Efectos de sonido & Creative Commons \\
\hline www.freemusicarchive.org & Música & Creative Commons \\
\hline www.pexels.com & Imágenes y videos & $\begin{array}{l}\text { Gratuita bajo con- } \\
\text { diciones }\end{array}$ \\
\hline www.storyblocks.com & $\begin{array}{l}\text { Imágenes, música, vi- } \\
\text { deos, gráficos }\end{array}$ & $\begin{array}{l}\text { Suscripción men- } \\
\text { sual/anual }\end{array}$ \\
\hline
\end{tabular}

Fuente: autores

\section{Iniciando en la edición básica de video}

La edición de video consiste en unir diversos materiales audiovisuales comofotografía, video, audio, animación, efectos, dentrodeun programa de computadora. La unión y manipulación de estos elementos dará vida a una idea para compartirla a través de las redes sociales o medios que vehiculan productos audiovisuales. En la industria audiovisual existen todavía dos formas de proceder con la unión de los diversos materiales audiovisuales. Dependiendo de la fuente estos procesos serán analógicos o digitales.

La edición analógica o edición lineal, de cinta a cinta, es relegada a escasos usos en el cine. El proceso analógico se usaba comúnmente en soportes físicos como el VHS o el Betamax. A partir de la década de los 80' se hace uso de un sistema digital el cual se volvió pronto el preferido de la industria y los aficionados al cine. (Konigsberg, 2004) 
El procedimiento es descrito como edición no lineal y existe gracias a la inserción de las computadoras, la grabación digital, y en los últimos años, el uso masivo de smartphones. En el mercado existen varias opciones en cuanto a programas de edición no lineal, entre gratuitos y pagados, profesionales y de edición básicos; estos usualmente son codificados para correr en la mayoría de sistemas operativos como Apple, Windows, Linux y Android.

Los programas profesionales de video requieren de mayor experticia y conocimientos y son utilizados para proyectos de video de alto costo en la televisión, el cine y los deportes. Los softwares de edición básica tienen mayor acogida en el público debido a que ofrecen herramientas básicas, fáciles de aprender y aplicar en cualquier proyecto audiovisual ya sea por un aficionado, un YouTuber o influencer de las redes sociales, incluso si esta no conoce nada de edición de video. Además, es posible aprender fácilmente a utilizar las herramientas mediante tutoriales que las mismas empresas y usuarios colocan en YouTube. (Miles, 2012) A continuación, se presenta un listado con programas recomendados en el mundo de la edición de video.

Tabla 4. Listado de programas de edición no lineal

\begin{tabular}{|l|l|l|l|}
\hline Software & Tipo de edición & Plataforma & Tipo de Licencia \\
\hline $\begin{array}{l}\text { AVID Media Com- } \\
\text { poser }\end{array}$ & Profesional & Windows, Mac & $\begin{array}{l}\text { Suscripción } \\
\text { mensual }\end{array}$ \\
\hline Adobe Premiere CC & Profesional & Windows, Mac & $\begin{array}{l}\text { Suscripción } \\
\text { mensual }\end{array}$ \\
\hline DaVinci Resolve & Profesional & $\begin{array}{l}\text { Windows, Mac, } \\
\text { Linux }\end{array}$ & $\begin{array}{l}\text { Gratuito y de un } \\
\text { solo pago }\end{array}$ \\
\hline $\begin{array}{l}\text { Adobe Premiere } \\
\text { Rush }\end{array}$ & Básica & $\begin{array}{l}\text { Windows, Mac, } \\
\text { Android, IOS }\end{array}$ & $\begin{array}{l}\text { Suscripción } \\
\text { mensual }\end{array}$ \\
\hline $\begin{array}{l}\text { Windows Movie } \\
\text { Maker }\end{array}$ & Básica & Windows & Gratuito \\
\hline
\end{tabular}




\begin{tabular}{|l|l|l|l|}
\hline Imovie & Básica & Mac & Gratuito \\
\hline $\begin{array}{l}\text { Wondershare Fil- } \\
\text { mora }\end{array}$ & Básica & Windows, Mac & $\begin{array}{l}\text { Gratuito y de } \\
\text { suscripción } \\
\text { mensual }\end{array}$ \\
\hline Kinemaster & Profesional & Android, IOS & $\begin{array}{l}\text { Gratuito y de un } \\
\text { solo pago }\end{array}$ \\
\hline
\end{tabular}

Fuente: autores

\section{Parámetros básicos para la edición no lineal de video}

Una vez que se disponga de todos los recursos necesario es imperante seleccionar el programa idóneo para la creación del video. Se sugiere utilizar Adobe Premiere Rush, una nueva herramienta de la familia de Adobe útil para dar los primeros pasos en el mundo de la edición de video. (Grisetti, 2019) El programa es pensado para desarrolladores de contenidos audiovisuales online, se puede utilizar en dispositivos móviles, tabletas y computadoras. Dispone de una interfaz rápida y dinámica que permite la creación de videos de una manera sencilla, usando herramientas básicas, efectos preestablecidos, textos, transiciones y otros elementos que permiten elevar la calidad del video. (Adobe, 2020) Terminada la edición es posible exportar el resultado final y subirlo directamente a YouTube o cualquier red social. Los pasos para usar el programa son idénticos en una computadora, una tableta o un teléfono inteligente. Para realizar una edición de video de forma básica en Adobe Premiere Rush es importante seguir algunos pasos:

\subsection{Arranque del programa}

Al dar inicio al programa este solicitara crear una cuenta en el sistema online de Adobe. La creación de esta cuenta da como ventaja la habilitación de un pequeño disco duro en la nube de la empresa 
de manera gratuita en el cual se puede almacenar cualquier tipo de contenido destinado para la edición. Luego el programa da la bienvenida y basta un clic en el recuadro "comenzar ahora" para dar inicio a la aventura.

Figura 1. Inicio correcto de la aplicación

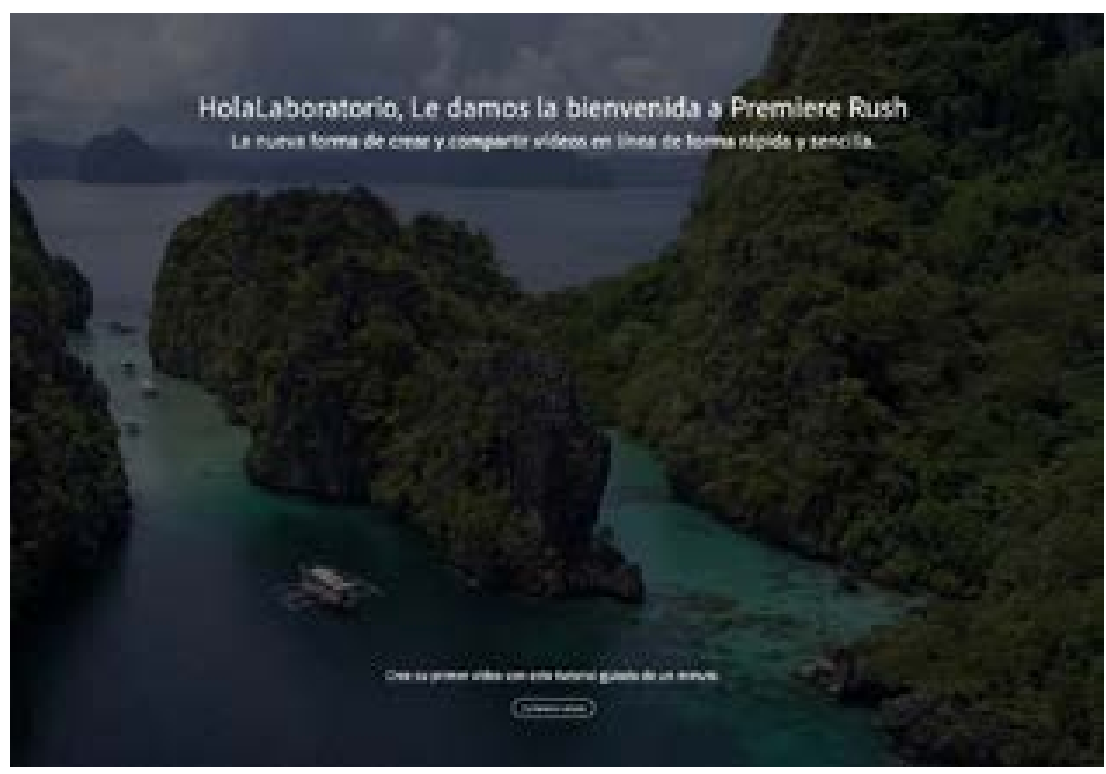

Fuente: Adobe Premier Rush

Adobe Premier Rush es capaz de guiar el usuario inexperto en el proceso de creación de su video mediante un tutorial incluido.

\subsection{Creación del proyecto y selección del material de trabajo}

Antes de iniciar se recomienda tener en una carpeta todo el material a editar (videos, audios, fotos, etc.) en el escritorio de tu PC con un nombre predeterminado. Cuando el programa se abre aparecerá 
un botón azul que dice "crear proyecto", al dar clic en ello se abrirán varias opciones que permitirán la creación del proyecto como tal. En la esquina inferior izquierda de la ventana el programa solicitará la asignación de un nombre al proyecto; también el usuario puede omitir la vista guiada que ofrece el programa. El programa por defecto tiene habilitada la pestaña de sincronización con el servicio de Creative Cloud, esto significa que todo el proyecto e inclusive sus materiales de trabajo serán almacenados en el disco duro que está en la nube y a su vez ligado a la cuenta de Adobe como se mencionó previamente.

\section{Figura 2. Asignación de un nombre para el proyecto}

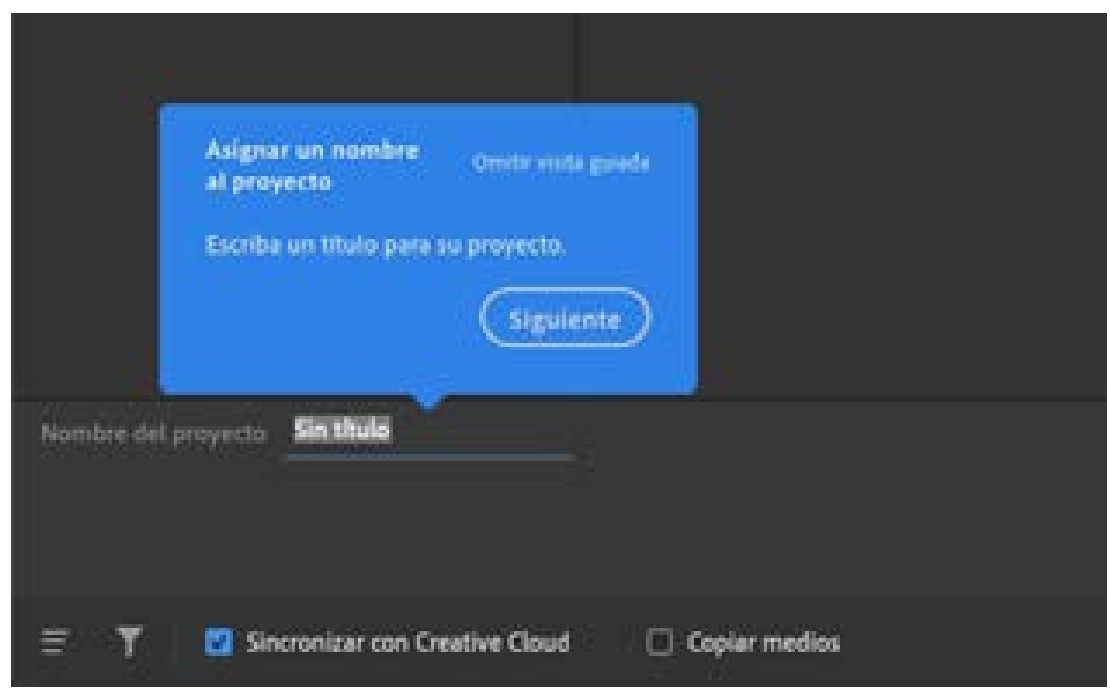

Fuente: Adobe Premier Rush

Para poder añadir los contenidos necesario para la elaboración del proyecto se abre la carpeta que contiene todos los archivos mediante el buscador del programa, lo que genera la visualización de los contenidos en la pantalla principal. Con un clic se seleccionan los elementos del 
video y se numeran en orden ascendente en base a la selección. Para crear la secuencia o pista principal del proceso de edición no lineal con todos los elementos seleccionados es suficiente un clic en el botón "Crear" que se encuentra en la esquina inferior derecha del programa.

\section{Figura 3. Selección de videos y creación de la secuencia con el material seleccionado}

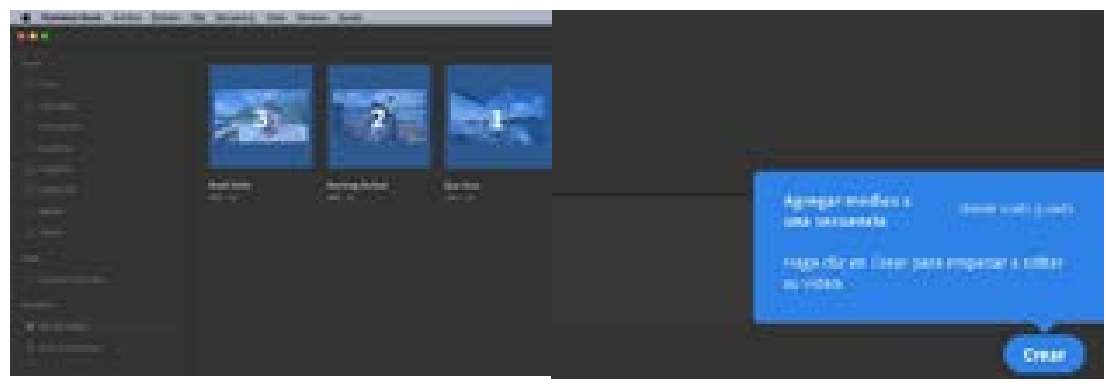

Fuente: Adobe Premier Rush

\subsection{Empezando con el proceso de edición}

Seleccionado el material a editar automáticamente se crea la línea de edición compuesta por los diferentes videos, audios, fotos y demás elementos en el orden en el que fueron seleccionados. Adobe Premiere Rush cuenta con una serie de herramientas básicas (Tabla 5) que facilitan el proceso de creación, ubicadas en la ventana principal del editor de video.

Tabla 5. Lista de las principales herramientas de Adobe Premiere Rush

\begin{tabular}{|l|l|}
\hline Tipo de herramienta & \multicolumn{1}{|c|}{ Acción } \\
\hline Cortar & Divide o corta un clip desde la parte que el usuario desea. \\
\hline Color & Modifica los colores del video o la imagen con total libertad. \\
\hline Titulo & Añade títulos o textos personalizados al video. \\
\hline Transiciones & Añade un nexo animado para unir dos videos con estilo único. \\
\hline
\end{tabular}




\begin{tabular}{|l|l|}
\hline Tiempo & Modifica el tiempo del video para hacerlo más lento o rápido. \\
\hline Basurero & Elimina un clip o elemento seleccionado. \\
\hline Agregar medios & Añade más elementos al video. \\
\hline Control de Pista & $\begin{array}{l}\text { Habilita el resto de las pistas para tener más libertad a la hora de } \\
\text { editar. }\end{array}$ \\
\hline Transformar & Modifica el ancho y alto del video o elemento seleccionado. \\
\hline Compartir & Exporta el video editado para subirlo a YouTube u otras redes. \\
\hline
\end{tabular}

Fuente: Adobe Premier Rush

El proceso de edición no lineal en Adobe Premiere Rush se basa en una pantalla de visualización que tiene una línea de tiempo que muestra el material audiovisual y las herramientas. El objetivo principal del editor es atribuir sentido a la historia en secuencia que se quiere contar, por lo cual el video debe basarse en una narrativa que disponga de una estructura básica: principio, desarrollo y final.

\section{Figura 4. Posición de cada una de las herramientas de edición}

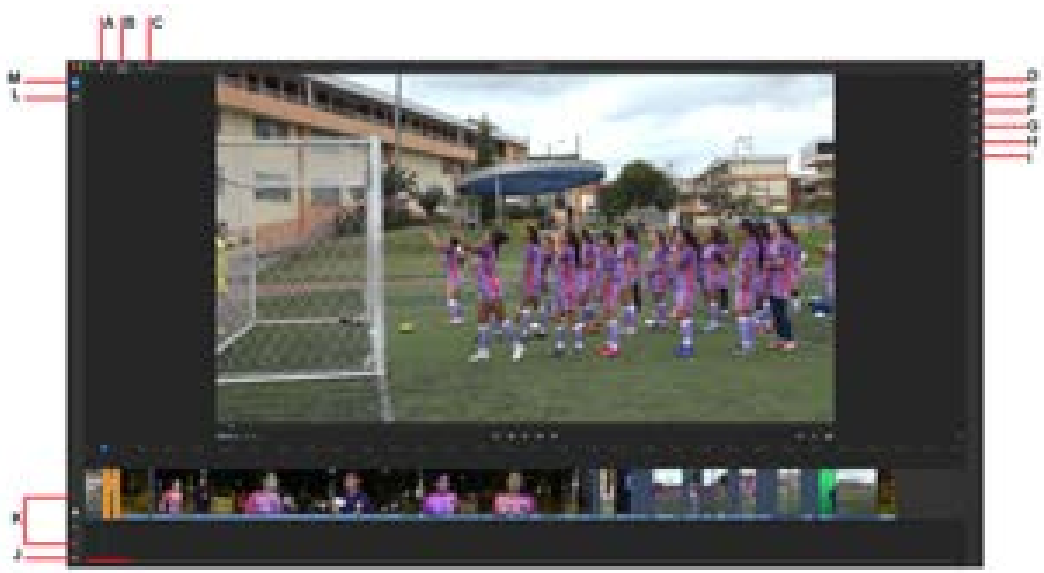

En la figura: A. Inicio B. Editar C. Compartir D. Título E. Transiciones F. Color G. Tiempo H. Audio I. Transformar J. Control de Pista K. Controles de Edición L. Panel de Proyecto M. Agregar medios. Fuente: autores 
Para tener más libertad creativa se recomienda habilitar la herramienta "Control de pista", lo que permite añadir cuatro pistas de video y tres pistas de audio en la línea de tiempo y mover con mayor facilidad los elementos de la mesa de edición en función del orden deseado.

\section{Figura 5. Ejemplo de edición no lineal en Adobe Premier Rush}

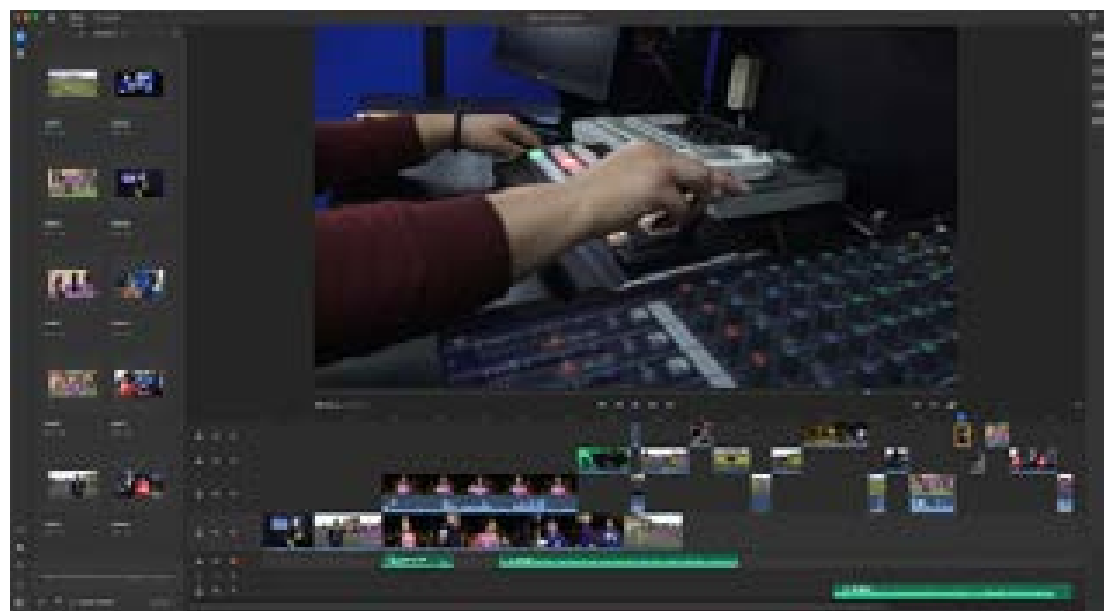

Fuente: autores

El programa ofrece herramientas útiles para mejorar aspectos como el color de los videos, modificar la velocidad del audio y las imágenes, controlar el volumen del audio, y aplicar transformaciones básicas como la ubicación en pantalla, tamaño, rotación, etc.

\subsection{Compartir el resultado final}

Una vez realizado el video puede ser difundido de varias formas, exportándolo localmente a la computadora, o compartiéndolo directamente mediante las redes sociales más populares. En este caso 
Adobe Rush permite publicar directamente en YouTube el video final simplemente iniciando sesión directamente en el programa. Una vez ingresado, se llenan los datos de publicación como el título, descripción, privacidad, seleccionando el formato del video a subir. Culminado con el proceso de exportación se puede visualizar en la cuenta de YouTube el video editado.

\section{Figura 6. Proceso para compartir videos en las redes sociales}

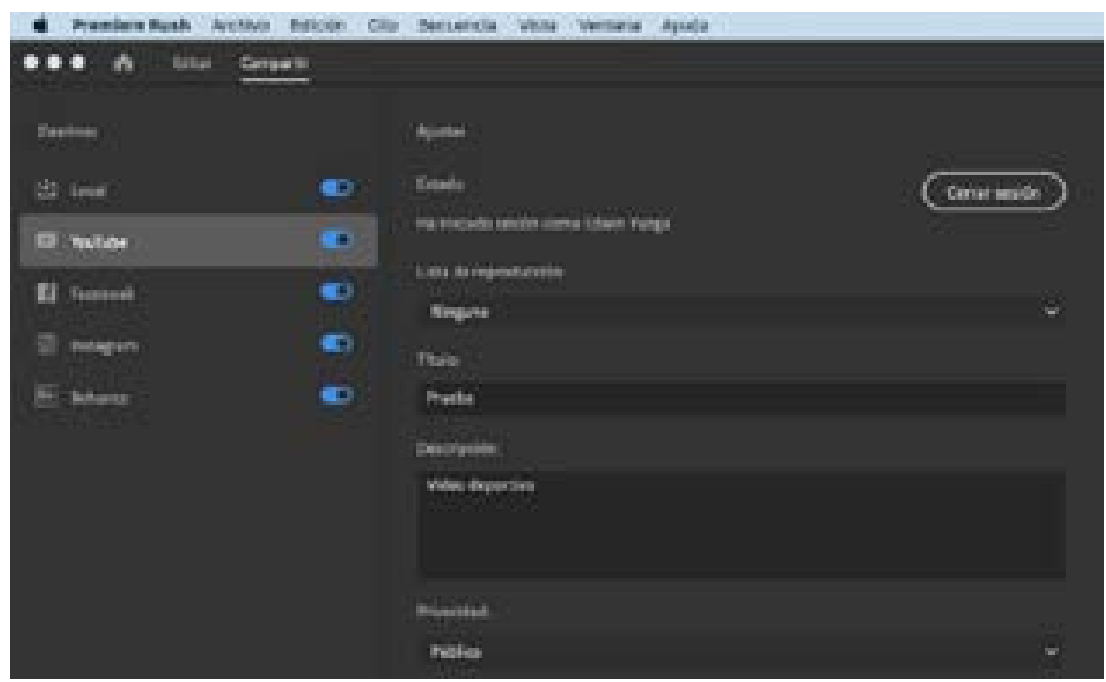

Fuente: Adobe Premier Rush

\section{Un futuro con más posibilidades}

En el mundo de la producción audiovisual la tendencia es marcada por el uso de aplicaciones que se basan inteligencia artificial para conseguir varios tipos de resultados que van desde la modificación del video hasta la mejora en cuanto a su calidad técnica. Existen varios usuarios 
de YouTube que han sido capaces de utilizar estas herramientas emergentes para realizar videos denominados como deep fakes, falsificaciones profundas basadas en el uso de los rostros de personas en los cuerpos de otras personas, con resultados bastantes realistas. Un ejemplo de los futuros avances en el campo de la producción audiovisual (Ortegón Quiñones y Machicao Valencia, 2020). Por otro lado, las empresas fabricantes de los chips gráficos que ayudan a procesar los videos en las computadoras han iniciado con el lanzamiento de servicios en línea que permiten alquilar un sistema de computadora que funciona mediante la conexión directa en Internet. Aunque por el momento estos servicios de suscripción se enfocan en el alquiler de sistemas dedicados a la reproducción de videojuegos, es posible que, en un futuro muy cercano, estas empresas opten por el lanzamiento de un sistema de computación en la nube que permita al usuario editar a través de cualquier dispositivo y que, por ende, dependa de la conexión a Internet. Esta proyección requiere de una necesaria mejora del servicio de conexión a la red con el fin de disminuir cualquier tipo de latencia entre el dispositivo principal y el servicio contratado en la red.

En cuanto a la tecnología móvil, los fabricantes están optando por la incorporación de procesadores que disponen de coprocesadores gráficos para la realización de tareas intensivas y que facilitan cualquier tipo de producción realizada mediante teléfonos inteligentes. Adjunto a esto se proyecta el aumento de la resolución de las cámaras de video a 8k, ofreciendo una calidad comparable a las cámaras profesionales de gama media que existen en el mercado. A pesar de todos los escenarios posibles, la tecnología actual otorga varias facilidades a los creadores de contenidos, pues hace 10 años era impensable realizar productos de calidad en poco tiempo y con herramientas no profesionales. YouTube no solo se adapta e interpreta los cambios tecnológicos ofreciendo nuevas oportunidades para que su comunidad logre cada vez mejores resultados en sus creaciones. 


\section{Referencias}

Adobe (2020). Adobe.com. Recuperado el 13 de Marzo de 2020 de https://www. adobe.com/la/

Bouillot, C. (2018). YouTube: La plataforma de vídeo que revoluciona el mundo digital. 5oMinutos.es.

Carrasco, J. (2010). Cine y televisión digital. Manual técnico. Barcelona, España: Universitat de Barcelona.

Cianci, P. J. (2012). High Definition Television: The Creation, Development and Implementation of HDTV Technology. Jefferson, USA: McFarland \& Co Inc.

Creative Commons (2020). Sobre las licencias. Lo que nuestras licencias hacen. Recuperado el 25 de Febrero de 2020 de https://creativecommons.org/licenses/?lang=es

Grisetti, S. (2019). The Muvipix.com. Guide to Adobe Premiere Rush: Simplified Moviemaking for Your Desktop Or Mobile Device. Independently Published.

Konigsberg, I. (2004). Diccionario Técnico Akal del cine. (Vol. 3). Madrid, España: Ediciones Akal.

Miles, J. (2012). Conquistar YouTube: 101 consejos de vídeo profesionales. Madrid, España: Anaya Multimedia.

Ochoa, L. (2016). Guía 4K 709. Tecnologías para la producción audiovisual en Ultra HD y 4 K. Madrid, España: Dykinson.

Ortegón Quiñones, E., y Machicao Valencia, J. C. (2020). Complejidad, inteligencia artificial y evolución en la gestión pública: Retos y oportunidades. Huancayo, Perú: Editorial Universidad Continental.

Serrano, P. (2017). La transformación digital de una redacción y el periodismo móvil (mojo): estrategia, herramientas y todos los secretos del periodismo móvil. Barcelona, España: Editorial UOC.

Torres Ripa, J., y Gómez Hernández, J. A. (2011). El copyright en cuestión: diálogos sobre propiedad intelectual. Bilbao, España: Publicaciones de la Universidad de Deusto. 